\title{
Genetically Engineered Strains: Application and Advances for 1,3-Propanediol Production from Glycerol
}

\section{Miaomiao Yang", Junhua Yun", Huanhuan Zhang", Tinashe A. Magocha, Hossain Zabed, Yanbo Xue, Ernest Fokum, Wenjing Sun and Xianghui Qi* \\ School of Food and Biological Engineering, Jiangsu University, 301 Xuefu Road, 212013 Zhenjiang, Jiangsu, PR China}

Received: July 29, 2017 Accepted: November 23, 2017

\section{*Corresponding author: \\ Phone: +8651188797059; \\ Fax: +8651188780201 ; \\ E-mail: qxh@ujs.edu.cn}

"These authors contributed equally to this work

ORCID IDs : 0000-0002-3253-7625 (Yang), 0000-0002-4319-2204 (Yun), 0000-0002-9042-619X (Zhang), 0000-0002-2754-1304 (Magocha), 0000-0001-6072-1289 (Zabed), 0000-00031239-4185 (Xue), 0000-0002-9191-2712 (Fokum), 0000-0001-5579-1944 (Sun), 0000-0002-5817-1609 (Qi)

Paper was presented at the 7 th International Forum on Industrial Bioprocessing - IFIBiop 2017, May 21-24, 2017, Wuxi, PR China

\section{SUMMARY}

1,3-Propanediol (1,3-PD) is one of the most important chemicals widely used as monomers for synthesis of some commercially valuable products, including cosmetics, foods, lubricants and medicines. Although 1,3-PD can be synthesized both chemically and biosynthetically, the latter offers more merits over chemical approach as it is economically viable, environmentally friendly and easy to carry out. The biosynthesis of 1,3-PD can be done by transforming glycerol or other similar substrates using some bacteria, such as Clostridium butyricum and Klebsiella pneumoniae. However, these natural microorganisms pose some bottlenecks like low productivity and metabolite inhibition. To overcome these problems, recent research efforts have been focused more on the development of new strains by modifying the genome through different techniques, such as mutagenesis and genetic engineering. Genetically engineered strains obtained by various strategies cannot only gain higher yield than wild types, but also overcome some of the barriers in production by the latter. This review paper presents an overview on the recent advances in the technological approaches to develop genetically engineered microorganisms for efficient biosynthesis of 1,3-PD.

Key words: glycerol, 1,3-propanediol, biosynthesis, genetically engineered strain, mutagenesis

\section{INTRODUCTION}

In recent years, sustainable development and resource recycling have become increasingly vital. With the popularity of biological production of commercially important metabolites, the biosynthesis of various products such as cosmetics, food, fuels, lubricants, plastics, beverages, fibres and medicines are put into practice (1). Biological approaches possess the huge potential to reduce the production of harmful bioproducts. The renewable resource biodiesel, which is derived from vegetable or animal fat transesterification, is a biodegradable and non-toxic fuel, representing an alternative source of energy. Crude glycerol is a major byproduct of biodiesel production. In consideration of the increasing global demand for biodiesel, there will be increasing crude glycerol produced $(2,3)$. The crude glycerol waste, if unable to be disposed or recycled in time, will not only raise the cost of biodiesel production, but also become a new source of pollution. For example, the emission of crude glycerol waste into aquatic habitat may destroy the aquatic ecological environment and endanger the survival of hydrobiose, weakening the fishing industry (4). Solutions have been offered to alleviate these environmental issues, for instance, the crude glycerol is required to be purified before discarding. However, the requirement for sophisticated equipment as well as increased costs of the purification process make it difficult to purify glycerol wastes (5). Therefore, the transformation to other specific chemicals by microorganisms has become a significant method for recycling this byproduct. 1,3-Propanediol (1,3-PD) is one of the most well-known biotechnological conversion products of glycerol by some specific bacteria, such as Lactobacillus brevis, Citrobacter freundii, Klebsiella pneumoniae, Enterobacter agglomerans, Clostridium pasteurianum, Clostridium butyricum and Clostridium beijerinckii (6-8). 
1,3-PD is colourless, tastes slightly sweet, and a viscous liquid easily miscible with water and ethanol $(9,10)$. It can be implemented as a monomer for the production of plastics with particular properties. For example, 1,3-PD can be the monomer of a new kind of polyester, namely polypropylene terephthalate (PTT), which can be efficiently used as a polyglycol-type lubricant. This property provides this polyester with extremely unique characteristics (11). Besides, 1,3-PD has been applied widely in many other industrial fields, such as the production of composites, adhesives, laminates, coatings, mouldings, aliphatic polyesters, and antifreeze (12,13). 1,3-PD can be produced through two kinds of chemical pathways: the hydroformylation of ethylene oxide and the hydration of acrolein $(11,14)$. However, many drawbacks like high consumption of energy, usage of expensive catalysts, and release of toxic intermediates increase its manufacturing cost by chemical methods. Therefore, biological methods of producing 1,3-PD with many advantages are used as an alternative way for making this process easier (15-17).

In biological production, the choice of appropriate co-substrates with glycerol for fermentation is of great importance, which can affect the yield of 1,3-PD. In previous studies, researchers have explored many co-substrates from different sources for glycerol bioconversion (18). For instance, Apiwatanapiwat et al. (19) cultivated a strain of $C$. butyricum on glycerol medium supplemented with cassava pulp. The results showed that the cassava pulp increased the productivity of 1,3-PD by almost $50 \%$ compared with the medium with glycerol as sole carbon source. Nevertheless, there are some other drawbacks of 1,3-PD conversion, such as the growth inhibition of bacterial cells, which increases with the increase in concentrations of glycerol or 1,3-PD $(20,21)$. Moreover, the toxic intermediate 3-hydroxypropionaldehyde (3-HPA), accumulated during fermentation along with other metabolites such as acetate, lactate, 2,3-butanediol and ethanol, also affects the cell growth $(22,23)$. Besides, expensive coenzyme $B_{12}$ may be needed in this process (24) (Fig. 1). Hence, the selection of an efficient microorganism to debottleneck this problem is another important factor.

Even though the wild type strains mentioned above showed a good ability to produce 1,3-PD, genetically engineered strains have shown a greater potential to improve their performance. As advanced evolution technology, genetic engineering methods like knockout and overexpression of relevant genes are used to create high-efficiency or high-productivity engineering strains (25). Moreover, conventional mutagenesis methods by some physical or chemical mutagens (single or complex) also provide a good way to alter the titres, yields or productivities. Therefore, in this study, genetic engineering methods and conventional mutagenesis methods for the production of 1,3-PD are chiefly reviewed. Also, recent development and prospects of these methods are briefly elaborated.

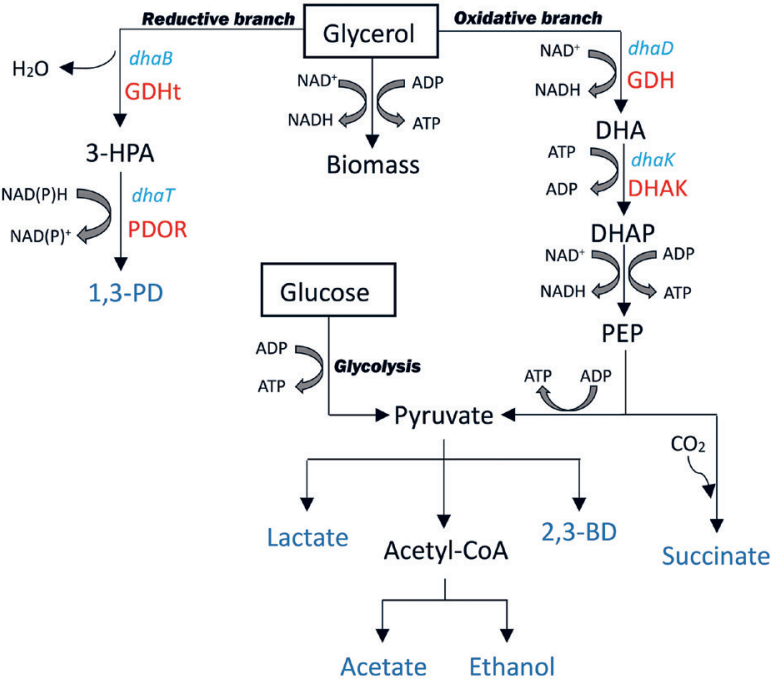

Fig. 1. Metabolic pathway of glycerol conversion (24)

\section{METABOLIC MECHANISMS OF 1,3-PD SYNTHESIS}

\section{Biological pathway for the synthesis of 1,3-propanediol}

In nature, 1,3-propanediol (1,3-PD) can only be produced from glycerol, i.e. glycerol dissimilation pathway is the sole pathway of 1,3-PD generation (26). Some microorganisms are able to use glycerol as the sole carbon source under anaerobic conditions. In these microbes, glycerol can penetrate the membrane in two different ways, by simple diffusion or by facilitated diffusion. The transmembrane protein of facilitated diffusion is a kind of glycerol transport facilitator called GlpF (TC 1.A.8.1.1) $(27,28)$. This facilitator selectively allows compounds (small neutral linear molecules) to pass through the cell membrane. When glycerol enters into the cell, it will be metabolized via two parallel fluxes: oxidative and reductive pathways.

In the oxidative branch, glycerol is oxidized to dihydroxyacetone (DHA, coded by dhaD), which is catalyzed by $\mathrm{NAD}^{+}$-dependent glycerol dehydrogenase (GDH). After this, DHA is phosphorylated by adenosine triphosphate (ATP)-dependent dihydroxyacetone kinase (DHAK, coded by dhaK) into dihydroxyacetone phosphate (DHAP), which enters into carbon flux towards glycolysis, TCA and other major metabolic pathways (24). Then, the converted pyruvate is metabolized further to produce the major cellular constituents, such as acetate, succinate, butyrate, lactate, ethanol, butanol, ethanol, 2,3-butanediol (2,3-BD), $\mathrm{CO}_{2}$ and $\mathrm{H}_{2}$.

The second, reductive branch leads to 1,3-PD formation (Fig. 2). In this branch, glycerol is initially reduced to 3-HPA catalyzed by glycerol dehydratase ( $\mathrm{GDHt}$, coded by $\mathrm{dhaB}$ ). The catalytic activity of this enzyme requires coenzyme $B_{12}$ to be an essential cofactor in most bacteria (in C. butyricum it is $B_{12}$-independent) (29). Afterwards, catalyzed by NADH-dependent 1,3-PD oxidoreductase (PDOR, coded by dhaT), 3-HPA is reduced to 1,3-PD. In the process of anaerobic conversion from glycerol to 1,3-PD, when all the acetyl-CoA enters the TCA cycle, with no 
acetate formed, a maximum theoretical yield of $0.875 \mathrm{~mol} / \mathrm{mol}$ is reached. However, in most cases, ATP is generated by formation of acetate, so the maximum theoretical yield with acetate as the sole byproduct is $0.72 \mathrm{~mol} / \mathrm{mol}$ (6).

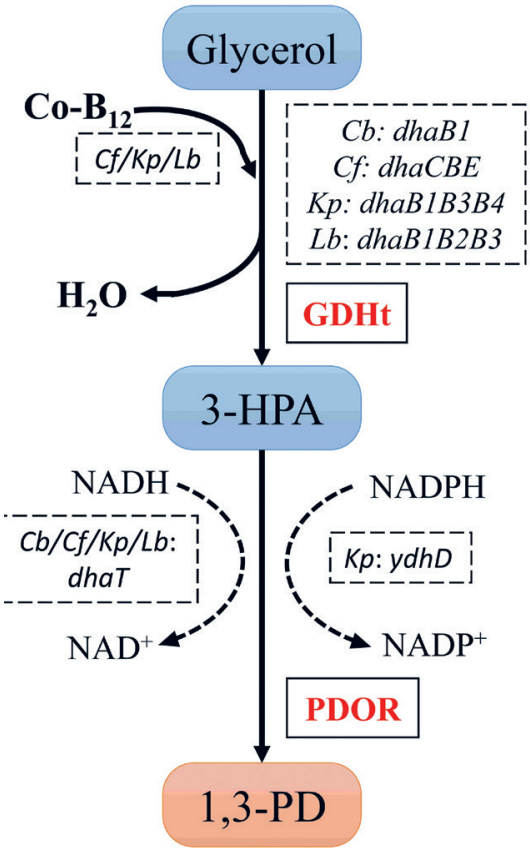

Fig. 2. Glycerol reductive pathway in various microbes: $K p=K l e b s i e l-$

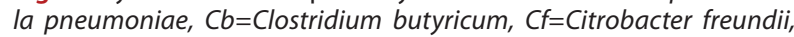
$C p=$ Clostridium pasteurianum, $L b=$ Lactobacillus brevis (6)

\section{The bottlenecks of glycerol bioconversion}

In the field of 1,3-PD bioproduction, there are many bottlenecks. Firstly, in the reductive branch of glycerol dissimilation, the synthesized intermediary compound 3-HPA is toxic to the bacteria and can prevent their growth. It has been widely applied as biological sterilization agent and anti-infection treatment agent. The exact mechanism is not very clear now (30). Besides, the two key enzymes of the branch, GDHt and PDOR are both susceptible to high concentrations of 3-HPA, which lowers their activity. As a result, the production of toxic 3-HPA in the culture media is triggered by a positive feedback mechanism, i.e. the increase of 3-HPA will repress the activity of GDHt in order to decrease the harmful effect of the toxicant. Hence, the decreased intermediates cause a low titre of the target product. This process triggers irreversible cessation of metabolic activity, which becomes a serious limitation to the 1,3-PD production process (31).

Secondly, the accumulation of 1,3-PD itself also inhibits cellular growth. Szymanowska-Powałowska and Kubiak (32) tested the effect of 1,3-PD in C. butyricum DSP1. 1,3-PD was added to the medium at the beginning of the cultivation prior to inoculation. The results showed that relatively high activity of the analyzed strain was maintained up to a concentration of 1,3-PD of $60 \mathrm{~g} / \mathrm{L}$. When exogenous 1,3-PD was added at an initial concentration of $80 \mathrm{~g} / \mathrm{L}$, it was lethal to the bacteria. Colin et al. (33) also studied the inhibitory effect of 1,3-PD in C. butyricum CNCM 1211. In their study, the tolerance levels were similar, and they discussed that the particular inhibitory effect of 1,3-PD was not related to osmotic pressure but rather to a modification of membrane organization by an increase in the fluidity of the membrane, causing the ethanol inhibition in microbial fermentation.

Finally, byproduct formation and maintaining redox balance is another bottleneck of 1,3-PD production. As shown in Fig. 1, in the metabolic pathway of glycerol, many kinds of other metabolites apart from 1,3-PD are generated simultaneously, becoming the byproducts of 1,3-PD production. In the oxidative branch, glycerol is transformed to phosphoenolpyruvate (PEP) through several steps catalyzed by some ATP-dependent oxidoreductases. For the mainstream metabolic pathway glycolysis, glucose is also transformed to PEP. Then PEP is catalyzed by pyruvate kinase to pyruvate, which fluxes to byproduct formation. Many factors can affect this process, such as external and genetic conditions. As a consequence, both quality and quantity of the byproducts are affected (28). Carbon from glycerol or glucose is consumed during the formation of these byproducts, resulting in a decrease in the titre of target product. Some of these byproducts are also toxic to the cells, inhibiting their growth. Therefore, the deletion of genes which cause the formation of these byproducts should be a good solution. However, these multiple pathways can adjust the balance of intracellular redox, i.e. the redox potential should be kept to stabilize the proteins when deleting these relative genes. The formation of unnecessary metabolites should be avoided and the balance of redox should be maintained. This is a challenge for the improvement of the product (34).

So far, researchers have attempted to debottleneck various steps of bioprocesses, and some progress has been made, but further attention should be paid to achieve more desired effects.

\section{GENETIC ENGINEERING METHODS}

Recently, genetic engineering has become increasingly popular. Inactivating or overexpressing the genes of the pathway of interest or the pathway favourably influencing the performance may overcome the barriers in 1,3-PD bioproduction. There are many advantages in genetic engineering, i.e. biochemical reactions can be modified specifically and the target strains can be designed to suit a particular purpose by the recombinant DNA technology. As a result of this modification of related genes, the product formation or cellular properties can be improved directly. Besides, the high throughput screening can be avoided. Constructing 1,3-PD engineering strains is a promising technology. A comparison between wild strains and various genetic engineering mutants in 1,3-PD production in recent years is shown in Table 1 (20,23,35-42). 
Table 1. Comparison of 1,3-propanediol production using various mutants by genetic engineering

\begin{tabular}{|c|c|c|c|c|c|c|}
\hline Method & Strain & Related gene & $\frac{\gamma(\text { titre })}{\mathrm{g} / \mathrm{L}}$ & $\begin{array}{c}Y \\
g / g\end{array}$ & $\begin{array}{l}\text { Ratio of titre (mutant to } \\
\text { wild type) }\end{array}$ & Reference \\
\hline \multirow{6}{*}{ Inactivation } & C. werkmanii DSM 17579 & $a d h E, d h a D$ and IdhA & 8.12 & 0.82 & 1.59 & $(20)$ \\
\hline & K. pneumoniae TC100 & $d h a D$ and $d h a K$ & 3.77 & 0.31 & 2.06 & $(23)$ \\
\hline & C. werkmanii DSM 17579 & dhaD & - & 0.74 & 1.50 & (35) \\
\hline & K. pneumoniae 2-1 & IdhA and ald & 87.5 & 0.70 & 1.10 & (36) \\
\hline & K. pneumoniae KG5 & poxB, pta and ackA & 76.8 & 0.54 & 1.15 & $(37)$ \\
\hline & K. pneumoniae J2B & $I d h A$ & 58.0 & 0.35 & 2.63 & (38) \\
\hline \multirow[t]{4}{*}{ Overexpression } & K. pneumoniae ME-308 & yqhD from $E$. coli & 67.6 & 0.51 & 1.25 & (39) \\
\hline & K. pneumoniae KG1 & dhat & 55.8 & 0.50 & 1.60 & $(40)$ \\
\hline & K. pneumoniae DSM 2026 & puuc & 16.8 & 0.42 & 2.16 & $(41)$ \\
\hline & K. pneumoniae AK & dhat & 25.9 & - & 1.88 & $(42)$ \\
\hline
\end{tabular}

$Y=$ yield

\section{Inactivation of genes}

The inactivation of genes associated with byproduct formation is an effective strategy exploited in metabolic engineering of 1,3-PD production (28,32). In oxidative branch of glycerol conversion mentioned above, many byproducts are formed. Among them, organic acids and ethanol are more toxic to bacteria than glycerol and 1,3-PD. A significant amount of the byproducts influences the ability of microbes to produce 1,3-PD. In addition, they cause high amount of energy consumption in downstream purification processes. Therefore, the elimination of byproduct formation is a good choice in 1,3-PD production. Gene knockout refers to a kind of genetic engineering modification by which one of the genes is made inoperative (30). The salient feature of this technology is that the biological function of a gene whose sequence is known but function unknown can be estimated by blocking the gene. It is also widely used by many researchers to inactivate the genes related to byproducts to improve the production (32). Careful consideration about which gene to be inactivated should be required.

\section{Inactivation of genes associated with DHA or DHAP}

The $d h a D$ gene encodes the $\mathrm{NAD}^{+}$-linked glycerol dehydrogenase $(\mathrm{GDH})$. GDH catalyzes the oxidation from glycerol to DHA. Furthermore, enzyme DHAK encoded by dhaK gene catalyzes the phosphorylation from DHA to DHAP. This is the first step of oxidation branch (24). During the biological production of 1,3-PD, the formation of byproducts increases the purification cost and time. In particular, similar boiling points of 2,3-BD and 1,3-PD make purification much more difficult. One solution is to inactivate the two genes associated with DHA and DHAP. Horng et al. (23) inactivated the $d h a D$ and $d h a K$ by genetic engineering strategy to prevent the byproduct accumulation during 1,3-PD production in K. pneumoniae. The mutant strain TC100 deficient in GDH activity was generated by insertion-deletion of a streptomycin resistance marker into the $d h a D-d h a K$ genes. The byproducts such as lactate, 2,3-BD and ethanol were not detected when this mutant was used for fermentation. The bacterial cells were cultured in $50-\mathrm{mL}$ flasks and incubated at $37^{\circ} \mathrm{C}$. The yield of 1,3-PD by TC100 was increased by about 2.06 times compared to the wild type strain after $48 \mathrm{~h}$ of incubation. However, this mutant produced less biomass and had smaller productivity of 1,3-PD than the parent strain, so the production was optimized by gene overexpression (mentioned below) and incubation conditions were adjusted to solve this problem.

Total elimination of byproduct formation in the oxidative branch decreases the biomass. In return, the decreased biomass affects the reductive branch of glycerol dissimilation pathway, resulting in the decrease of 1,3-PD yield. The reason is that in the glycerol dissimilation pathway, the formation of byproducts in the oxidative branch provides reductive power for 1,3-PD synthesis (34). The problem that total elimination causes low 1,3-PD yield can also be solved by disconnecting the production and growth pathways. Maervoet et al. (35) studied the 1,3-PD production of Citrobacter werkmanii. Genetic tools were used to create $C$. werkmanii DSM $17579 \Delta d h a D$, in which $d h a D$ gene was deleted. The mutant strain used glucose and glycerol to increase the biomass. As a result, the 1,3-PD yield on glycerol was improved 1.5 times.

Inactivation of genes associated with pyruvate reduction

Lactate is one of the byproducts of the reduction of pyruvate, which requires one molecule of $\mathrm{NADH}$. It is a major byproduct in glycerol fermentation shunting the carbon flow away from pyruvate and leading to the decrease of 1,3-PD yield (26). During cell growth, lactate is accumulated in the late exponential phase, which prevents cellular growth. Therefore, many researchers have obtained lactate-deficient mutants so far to prevent the synthesis of lactate, which is of great significance for 1,3-PD fermentation (36-38). The concrete practice is knocking out the IdhA gene encoding lactate dehydrogenase. In addition, 2,3-BD is another main byproduct of the reduction of pyruvate in glycerol-based fermentation. As 2,3-BD is also a diol like 1,3-PD, they have similar boiling points and 1,3-PD is very hydrophilic (37). Therefore, this causes a serious obstacle to efficiently separate highly pure 
1,3-PD from 2,3-BD. Naturally, the deletion of genes associated with $2,3-\mathrm{BD}$ is a good idea to change this phenomenon and decrease the cost of purification.

Durgapal et al. (38) examined the ability of $K$. pneumoniae J2B to produce 1,3-PD from glycerol. In their study, a lactate dehydrogenase-deficient mutant was constructed. The wild type and $\Delta / d h A$ mutant strain were grown and compared under different culture conditions and different cultivation mode (batch or fed-batch). When K. pneumoniae $\Delta / d h A$ was cultivated in glycerol fed-batch mode, a promising result was obtained: the titre of 1,3-PD was $58.0 \mathrm{~g} / \mathrm{L}$ with a yield of $0.35 \mathrm{~g} / \mathrm{g}$ and an overall volumetric productivity of $1.3 \mathrm{~g} /(\mathrm{L} \cdot \mathrm{h})$. The analysis of carbon balance suggested that the $\triangle l d h A$ mutant strain produced negligible lactate but more 2,3-BD than wild strain. 2,3-BD became the main byproduct (the titre was $26.6 \mathrm{~g} / \mathrm{L}$ ) and less than $10 \mathrm{~g} / \mathrm{L}$ of the other metabolites was detected. Therefore, in the following study (43) they deleted the 2,3-BD pathway genes, budA, budB, budC and budO (whole-bud operon) of K. pneumoniae J2B $\Delta / d h A$. The result showed that the strain $\triangle b u d \mathrm{O}$ eliminated 2,3-BD production completely but generated less 1,3-PD. It was shown that the accumulation of a significant amount of pyruvate is probably responsible for the decrease of 1,3-PD production. Some other research groups (40-42) also paid attention to the deletion of both IdhA gene and genes associated with 2,3-BD, such as als gene encoding acetolactate synthase in the biosynthesis of 2,3-BD. Oh et al. (44) focused on the mutants of $K$. pneumoniae with deletions of the als and IdhA genes. However, when using the mutants for producing 1,3-PD in the fed-batch fermentation, only the $\Delta / d h A$ strain was able to produce the maximum 1,3-PD (102.7 $\mathrm{g} / \mathrm{L})$.

Inactivation of genes associated with acetyl-CoA reduction

Not only does the carbon flow from pyruvate to lactate, but it also flows to acetyl-CoA. As a result, many byproducts are produced. In the metabolic process of pyruvate, catalyzed by aldehyde dehydrogenase, acetyl-CoA is a significant mid-product. Afterwards, acetyl-CoA is reduced to other metabolites like acetate, ethanol and butyrate (22). Many kinds of mutants which are deficient in these byproducts have been developed $(20,36)$.

Acetate is an inhibitory metabolite to cellular growth. Among these metabolites from acetyl-CoA, acetate is the most toxic (26). Therefore, elimination of acetate synthesis is the most significant target in metabolic engineering of 1,3-PD production. Lin et al. (37) studied the effects of deletion of the genes pox $B$ encoding pyruvate oxidase, pta encoding phosphotransacetylase and $a c k A$ encoding acetate kinase on cell growth and 1,3-PD yield of K. pneumoniae. These genes are all involved in the two main acetate synthesis pathways. The final 1,3-PD titre in the fed-batch fermentation reached $76.8 \mathrm{~g} / \mathrm{L}$, which was $15 \%$ higher than that of wild strain. These deletions severely decreased the formation of acetate and more carbon flowed to TCA cycle, and as a result the production of 1,3-PD was enhanced.
Ethanol is another key competitor to the formation of 1,3-PD (39). The formation of ethanol begins with the transformation from acetyl-CoA to acetaldehyde catalyzed by aldehyde dehydrogenase (encoded by aldH). Then, with catalyzed ethanol dehydrogenase (encoded by adhE), acetaldehyde is reduced to ethanol. This process needs four molecules of NADH. NADH acts as co-enzyme in the formation of ethanol, decreasing the quantity of NADH in reductive branch (28). The elimination of lactate combined with ethanol synthesis is also a promising method. In order to improve 1,3-PD production by K. pneumoniae, Chen et al. (36) deleted the relative genes and obtained $K$. pneumoniae 2-1 $\Delta / d h A$, K. pneumoniae 2-1 $\Delta$ ald $H$ and $K$. pneumoniae 2-1 $\Delta / d h A \Delta a l d H$ mutant strains. In a fed-batch culture, the production of 1,3-PD from glycerol was enhanced and the concentrations of byproducts were reduced compared with the original strain K. pneumoniae 2-1. The maximum titres of 1,3-PD were 85.7, 82.5 and $87.5 \mathrm{~g} / \mathrm{L}$ compared with $78.8 \mathrm{~g} / \mathrm{L}$ of the parental strain. Maervoet et al. (20) deleted the gene adhE singly, doubled with $d h a D$, and tripled with dhaD and IdhA in C. werkmanii. The single knockout showed that the yield of 1,3-PD was $0.7 \mathrm{~mol} / \mathrm{mol}$ glycerol, while the yield obtained by the use of wild strain was $0.63 \mathrm{~mol} / \mathrm{mol}$. The result of double knockout was $0.96 \mathrm{~mol} / \mathrm{mol}$ and of triple knockout was $1.0 \mathrm{~mol} / \mathrm{mol}$. The most promising result was that the maximum theoretical yield of $1.00 \mathrm{~mol} / \mathrm{mol}$ glycerol and a final titre of (107.20 \pm 4.2$)$ $\mathrm{mmol} / \mathrm{L} \mathrm{1,3-PD}$ was reached when grown in shake flasks with glucose and glycerol as carbon sources under anaerobic conditions (20).

\section{Overexpression of genes}

In addition to the inactivation of genes, many researchers have tried to optimize production via the overexpression of reductive pathway (45). As the name implies, the overexpression of genes is an abnormally and excessively high level of gene expression which produces a pronounced gene-related phenotype (46). The salient feature of overexpression is that the process can be carried out not only in the original cells where it exists (homologous host), but also in another expressing system (heterologous host). The target genes to be overexpressed can be obtained from both the same producers and other existing cells (47).

Overexpression of genes associated with the original pathway

In the reductive branch of glycerol dissimilation, the two key enzymes, GDHt and PDOR, are encoded by dhaB and dhaT, respectively. As a result, the activity of the two enzymes can be enhanced and 1,3-PD yield can be increased as well. In addition, the enzyme PDOR is NADH-dependent (24). When the byproduct pathways were deleted, the intracellular redox balance (NADH/NAD ${ }^{+}$) was extremely high in these mutants, which has already been confirmed by some researchers. Therefore, these groups investigated further 
how to overexpress genes $d h a B$ and $d h a T$ to use these saved $\operatorname{NADH}(46,48)$.

In the study of Cui et al. (40), the dhaT gene was overexpressed in two mutants of K. pneumoniae, KG1-3T (blocking of the 2,3-butanediol pathway only) and KG1-5T (blocking of both 2,3-BD and lactate pathways). The results showed that in KG1-5T, the redox balance was restored to normal and 1,3-PD yield was enhanced. The yield of 1,3-PD from glycerol in KG1-5T was restored to the normal level of 0.6. Oh et al. (42) first obtained a mutant of K. pneumoniae without the byproduct formation by deleting the oxidative branch of glycerol. Then, they studied the overexpression of the $d h a B$ and/ or dhaT genes in this mutant to improve the 1,3-PD yield. The results suggested that the mutant overexpressing dhaT alone gained the highest yield of the three mutants. In fed-batch fermentation, efficient production of 1,3-PD from either pure or crude glycerol was gained and no byproducts were formed.

\section{Overexpression of genes apart from the original pathway}

Many researchers are seeking other methods that do not focus on the original 1,3-PD pathway. One of them is to clone the genes encoding the enzymes involved in the 1,3-PD synthesis pathway found in other natural strains of bacteria (49). Heterologous recombinant strains can also be constructed by metabolic engineering. These genes are expressed and isozymes are obtained for 1,3-PD fermentation. For example, yqhD gene from $E$. coli can encode an oxidoreductase which was found to possess the same function as PDOR from $K$. pneumoniae, and was thus considered as 1,3-PD oxidoreductase isoenzyme (PDORI) (32). Many researchers investigated this gene and cloned it into 1,3-PD producers to increase the yield. Zhu et al. (39) used a K. pneumoniae mutant with overexpression of PDORI, which surprisingly led to higher 1,3-PD production. The final 1,3-PD concentration of recombinant $K$. pneumoniae reached $67.6 \mathrm{~g} / \mathrm{L}$, which was $125.33 \%$ of that by the parent strain and the yield reached $0.62 \mathrm{~mol} / \mathrm{mol}$. The conversion activity of the enzyme in the recombinant mutant was detected. The maximum was increased 10-fold compared with the wild strain under the same conditions. Besides, the concentration of the toxic intermediate 3-HPA was reduced by $22.4 \%$ when compared to the original strain. Therefore, the overexpression of genes can also solve the inhibitory problem posed on the cell growth by the intermediary metabolite 3-HPA in the reductive branch of glycerol dissimilation.

Another method to decrease the concentration of 3-HPA during 1,3-PD fermentation is to convert 3-HPA to other metabolites (42). For example, the gene of an $\mathrm{NAD}^{+}$-dependent $\gamma$-glutamyl- $\gamma$-aminobutyraldehyde dehydrogenase (PuuC) of $K$. pneumoniae can be overexpressed. This enzyme is able to oxidize 3-HPA to 3-hydroxypropionic acid (3-HP). In that study puuC gene was cloned and overexpressed in K. pneumoniae DSM $2026 \Delta d h a T$ (41). The recombinant puuC gene mutant can successfully produce $3.6 \mathrm{~g} / \mathrm{L}$ of 3-HP in shake flask culture. In fed-batch fermentation, the recombinant $K$. pneumoniae $\Delta d h a T$ (puuC) strain produced $16.0 \mathrm{~g} / \mathrm{L}$ of $3-\mathrm{HP}$ and $16.8 \mathrm{~g} / \mathrm{L}$ of $1,3-\mathrm{PD}$. The yield in $24 \mathrm{~h}$ reached $0.51 \mathrm{~mol}$ per mol of glycerol.

As it is mentioned above, in order to gain better producers, the inactivation or overexpression of more than one gene can be carried out. Besides, knocking out the genes encoding the production of byproducts and overexpressing useful genes simultaneously can give different advantages. Some other new biotechnology tools like genome shuffling, which can also be combined with inactivation or overexpression, could probably make the producers more efficient. Due to the modification of gene or even the genome, there are some limitations of these methods, for example, metabolic disorders may occur. These joint methods and related problems deserve attention in the future (26).

\section{CONVENTIONAL MUTAGENESIS METHODS}

Induced mutation is one of the conventional and classical mutation methods in microorganism breeding field, which significantly improves the frequency of spontaneous mutation by mutagens encompassing physical or chemical factors. Although induced mutation is a random mutagenesis, it is extensively used not only in highly productive industrial strains, but also in altering metabolic pathway of wild type strains to gain new metabolites or to express a particular phenotype (50). Therefore, these induced agents were carried out singly or jointly with the purpose of efficiency improvement in bioconversion from glycerol to 1,3-PD. The mechanisms of induced mutation are diverse and can be classified into point mutation (the effect of one base pair) and aberration (the effect of a length of chromosome). The performance of different mutants is given in Table 2 (50-55).

\section{Physical mutagenesis}

\section{Ultraviolet rays}

Ultraviolet radiation is a simple and effective method of mutagenesis, and the effective UV wavelength for treatment is $200-300 \mathrm{~nm}$. Among these wavelengths, $254 \mathrm{~nm}$ is the optimum one, because it is the maximum absorption of nucleic acid. Ultraviolet radiation can cause base transitions, transversions, frameshift, mutation or deletion, resulting in the formation of mutants $(56,57)$. Most researchers $(50,54)$ had accomplished the UV mutagenesis of strains producing 1,3-PD directly by ultraviolet lamp irradiation. The distance, time and power of UV irradiation can affect the mutagenesis ratio. The UV parameters were investigated at different levels, and the appropriate level was determined by the mortality rate. The optimal mortality rate should be $90-95 \%$ (58). Afterwards, the selected parameters were used to make mutants and the ideal mutants were screened. By this pattern, Lu et al. (50) chose K. pneumoniae as the focus of their research, in which UV mutagenesis of its protoplast was induced, in order to improve the tolerance of the strain to glycerol and 
Table 2. Comparison of 1,3-propanediol production using various mutants by conventional mutagenesis methods

\begin{tabular}{|c|c|c|c|c|c|c|}
\hline Method & Mutagen & Strain & $\frac{\gamma \text { (titre) }}{\mathrm{g} / \mathrm{L}}$ & $\frac{Y}{g / g}$ & $\begin{array}{l}\text { Ratio of titre (mutant } \\
\text { to wild type) }\end{array}$ & Reference \\
\hline \multirow[b]{2}{*}{ Physical mutagenesis } & UV rays & K. pneumoniae ATCC 25955 & 75.51 & 0.51 & 1.35 & $(50)$ \\
\hline & DBD plasma & K. pneumoniae KрМ30 & 70.20 & 0.48 & 1.25 & (51) \\
\hline \multirow{4}{*}{ Chemical mutagenesis } & UV and $\mathrm{LiCl}$ & K. pneumoniae YMU1 & 69.54 & 0.42 & 1.63 & $(52)$ \\
\hline & NTG & C. diolis DSM 15410 & 85 & 0.64 & 1.8 & (53) \\
\hline & UV and $\mathrm{LiCl}$ & K. pneumoniae LM03 & 66.74 & - & 1.33 & $(54)$ \\
\hline & DES & C. butyricum ASL209 & 15.70 & - & 6.13 & $(55)$ \\
\hline
\end{tabular}

$Y=$ yield, $\mathrm{DBD}=$ dielectric barrier discharge, NTG=N-methyl-N'-nitro-N-nitrosoguanidine, $\mathrm{DES}=$ diethyl sulfate

1,3-PD, and thus to obtain strains with high 1,3-PD production. Two methods were designed to obtain the protoplast of $K$. pneumoniae. The samples were pretreated with glycine and then dissolved with lysozyme. After the mutagenesis of protoplasts, three high-yield strains (pK-1, K-4 and K-5) were obtained because of their tolerance to high concentration of glycerol and 1,3-PD. In fed-batch fermentation experiments, the 1,3-PD titres of pK-1, K-4 and K-5 were 70.24, 65.21 and $75.51 \mathrm{~g} / \mathrm{L}$, respectively. Compared with the wild strain, whose production was $55.78 \mathrm{~g} / \mathrm{L}$, the 1,3-PD production of mutant strains was improved by 25.92, 16.91 and $35.37 \%$, respectively. As a very common physical mutagen, ultraviolet radiation is always combined with other chemical mutagens to obtain better producers.

\section{Dielectric barrier discharge plasma}

Atmospheric pressure cold plasma is a non-equilibrium plasma at low temperature, which is the plasma at atmospheric pressure when gas is ionized by the influence of external high energy, i.e. high voltage, strong magnetic field, radiation, etc. Gas can produce a large number of active substances in the ionization process, including charged particles, metastable substances with chemical activity, such as ozone, activated hydroxyl radicals, oxygen atoms, and ultraviolet photon (59). These substances can interact with biological molecules and organisms like enzymes and DNA. Plasma can cause oxidative damage of DNA, leading to the damage of DNA double chain structure and to the death or mutation of organisms (60).

So far, the use of dielectric barrier discharge (DBD) plasma mutagenesis on 1,3-PD production has been reported (51). Dong et al. (61) used this method to evaluate K. pneumoniae strain with the capacity of producing 1,3-PD. Fig. 3 shows the diagram of DBD device they used, consisting of power supply and reactor. The reactor consists of a pair of circular aluminium plate electrodes covered with quartz glass. The cell suspension can be spread on the quartz glass and then treated with DBD plasma.

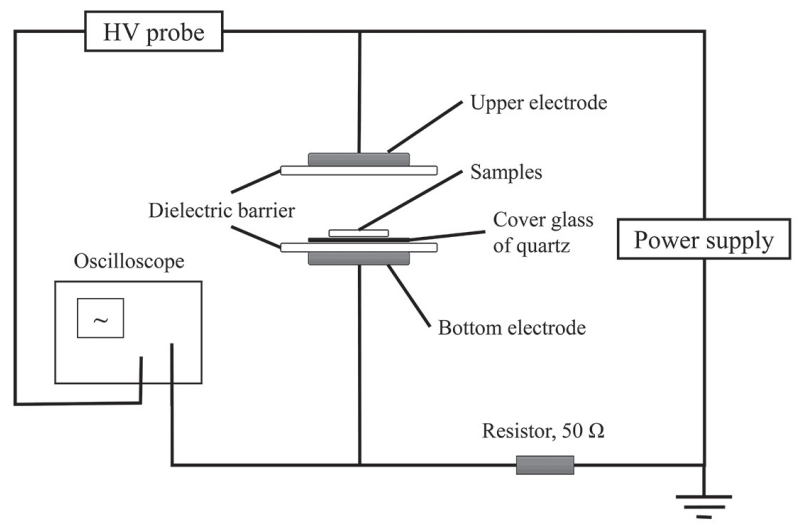

Fig. 3. Schematic diagram of the dielectric barrier discharge plasma device at atmospheric pressure (51)

DBD plasma was used as a single mutagenesis agent and a stable strain of $K$. pneumoniae (designated Kp-M2) was generated with improved 1,3-PD production. The strain was obtained by exposing the cells to DBD plasma before subjecting them to fermentation with glycerol as a carbon source. In batch fermentation, Kp-M2 strain grew faster and consumed glycerol more rapidly than the wild type. The final yield of 1,3-PD was enhanced by $23 \%$. In fed-batch fermentations, Kp-M2 also showed faster growth than wild type. Furthermore, in another work (51), a complex treatment of plasma and $\mathrm{LiCl}$ was attempted, and a mutant strain designated $\mathrm{KpM} 30$ was obtained in a medium containing $\mathrm{FeCl}_{3}$ with selective pressure. The mutant showed a high titre of 1,3-PD (70.2 g/L, increased by $24.9 \%$ compared with the wild strain), and its yield on glycerol was $0.576 \mathrm{~mol} / \mathrm{mol}$, increased by $17.7 \%$ in fed-batch fermentation. Briefly, DBD plasma has antibacterial activity, the biological effect of improving seed vigour, as well as the unique potential of mutagenesis (62). 
Other physical agents

So far, there have been many other new physical mutagenesis means applied to microbial breeding, and good results have been achieved (63). For example, mutants can be obtained by the X-ray, neutron, ion implantation, microwave, ultrasonic or laser radiation, cosmic rays, etc. C. beijerinckii is used for butanol fermentation from a non-detoxified hemicellulosic hydrolysate of corn fibre treated with diluted sulfuric acid (SAHHC). This fermentation has similar bottlenecks in 1,3-PD production, i.e. both the substrate inhibitor and the product inhibitor. Therefore, in order to overcome these disadvantages, low-energy ion implantation technology was introduced to butanol fermentation. Guo et al. (64) used this technology to carry out the reconstruction of $C$. beijerinckii. As a result, they obtained mutant IB4, which had a high level of tolerance to the inhibitor. However, until now there have been few reports about the application of these new mutagenesis methods in the transformation of glycerol to 1,3-PD. The above examples can provide references for improving the tolerance of 1,3-PD and improving its yield.

\section{Chemical mutagenesis}

Lithium chloride

Lithium chloride ( $\mathrm{LiCl})$ is an alkali metal halide, which has no direct mutagenic effect by itself, but when combined with other mutagens, it often has good synergistic mutagenic activity (65). $\mathrm{LiCl}$ is usually used in combination with UV mutagenesis in breeding. Du et al. (52) obtained mutants by UV light and $\mathrm{LiCl}$ mutagenesis derived from the parent strain of $K$. pneumoniae. In this study, a novel redox potential (oxidoreduction potential [ORP])-based screening strategy was designed for the isolation of mutants with high 1,3-PD production. LiCl was added to Luria-Bertani (LB) culture medium plates at a concentration of $2 \mathrm{~g} / \mathrm{L}$. Then the cell suspension in exponential growth phase was spread on these plates, which were put $40 \mathrm{~cm}$ below the UV light source (30 W) for $30 \mathrm{~s}$. Under the above conditions, approx. 5 out of 100 cells survived. 1,3-PD was measured by high-performance liquid chromatography after incubation at $37^{\circ} \mathrm{C}$ in the dark for 48 h. The highest 1,3-PD concentration of the mutant was 915 $\mathrm{mM}$, i.e. $69.54 \mathrm{~g} / \mathrm{L}$, which was $63.1 \%$ higher than that of the wild strain. The distribution of metabolic flux analysis of this mutant indicated that the strengthened bioreductive branch contributed to the improved production of 1,3-PD. Wang et al. (54) also chose $\mathrm{LiCl}$ combined with other physicochemical agents to induce $K$. pneumoniae mutagenesis. Based on ion ray, ultraviolet light and $\mathrm{LiCl}$ mutation methods, product tolerance was increased, and as a result of that the conversion ability of glycerol into 1,3-PD also increased. Compared with parent strain, the production of the two mutants LM03 and LM05 was improved by 33 and $30 \%$ respectively. A large number of studies suggests that the rate of positive mutation by $\mathrm{LiCl}$ is much higher than the single UV mutagenesis, and protoplast mutagenesis by UV combined with $\mathrm{LiCl}$ is more liable than mycelium mutagenesis to obtain the high yield strains $(52,58,65,66)$.

\section{$\mathrm{N}$-methyl-N'-nitro-N-nitrosoguanidine}

$\mathrm{N}$-methyl-N'-nitro-N-nitrosoguanidine (NTG) is an alkylating mutagenesis agent, which is a commonly used chemical mutagen. Many researchers focusing on NTG mutagenesis have found that NTG makes a strong preference for $\mathrm{G} / \mathrm{C}$ to A/T transitions (63). In 1995, NTG was used for the mutagenesis of $C$. butyricum with the purpose of decreasing the substrate and product inhibition (67). In fed-batch culture, 44 $\%$ more glycerol was consumed and $50 \%$ more 1,3-PD was produced by the mutant than by the wild type strain. Otte et al. (53) also used NTG as mutagen to enhance the yield of 1,3-PD by C. diolis DSM 15410 in a single-cell suspension. The cells were first treated with NTG solution for over $1 \mathrm{~h}$ at $34^{\circ} \mathrm{C}$, then centrifuged and resuspended. Finally, they were spread onto agar plates containing different concentrations of 1,3-PD for tolerance screening, and higher yield producers, mutant 44 and 46, were obtained. Combined with genome shuffling (directed evolution of whole organisms via recursive recombination at the genome level), an excellent producer with a 1,3-PD yield of $85 \mathrm{~g} / \mathrm{L}$ was obtained, which is 80 $\%$ higher than that of the parental wildtype strain.

\section{Diethyl sulfate}

Diethyl sulfate (DES) is another widely used alkylating mutagenesis agent. Using C. butyricum 209 as the original strain, Li et al. (55) obtained a mutant strain whose 1,3-PD yield was increased to $113 \%$ by two rounds of DES mutagenesis. UV mutagenesis alone and UV combined with NTG mutagenesis of this mutant were both carried out. 1,3-PD titre of the final mutant reached $15.7 \mathrm{~g} / \mathrm{L}, 6.13$ times higher than the original strain (the titre was $2.2 \mathrm{~g} / \mathrm{L}$ ). They used the single cell suspension method. Solid crystal can also be used in random chemical mutagenesis. A crystal of mutagen was placed at the centre of each plate. Two plates without the mutagen were used as the control. After several minutes, liquid strain culture was spread on each plate, which were then incubated until bacterial growth was observed (68).

There are just a few simple physical agents used currently for the conventional mutagenesis. Technologies like atmospheric and room temperature plasma have been used to produce new strains, and good results were obtained (52). Therefore, complex agents or other violent factors are a promising choice. In summary, these conventional mutagenesis methods provide good choices to obtain high-productivity industrial strains or express a particular phenotype. Moreover, some disadvantages are also obvious. For example, these methods are random, and the mutation rate is much lower than when using genetic methods. High throughput screening should be used to isolate the positive strains, which enlarges the working capacity. Therefore, proper attention should be paid to more efficient screening methods. 


\section{FERMENTATION PROCESSING}

\section{Genetic stability of engineered strains}

The stability of the genetically engineered strains mentioned above was investigated to determine their behaviour in practical fermentation $(45,69)$. After culturing for several generations, the titre or yield and the activity of key enzymes of 10-100 passages were still identical to that of passage 0 , which indicated that the recombinants had good genetic stability. However, in the study of some strains like Kp-M1 and Kp-M7 (69), their longevity profile was not very good $(70,71)$. In order to increase their stability and make their repeated or continued use possible, many researchers adopted different methods to maintain the biological activity of engineered strains. The first is to continuously conduct mutagenesis generation by generation (69). The second is to carry out stress treatment by adding the inhibitors like glycerol and 1,3-PD into the fermentation broth (68). However, the most promising technique is immobilization of cells (31). The cells are fixed into a solid matrix or retained by a membrane. Apart from the fact that the stability of the enzyme is increased, cell immobilization also makes it possible to maintain the primitive state and high recovery rate of the enzyme, and the coenzyme factor can be added automatically. It has been demonstrated that cell immobilization techniques can significantly increase 1,3-PD production and allow robust continuous production (31). Therefore, fermentation by using immobilized microorganisms is a great way to keep the longevity and stability of the biomass.

\section{Different fermentation approaches}

1,3-PD was mostly produced under anaerobic conditions, however, facultative anaerobic or microaerobic conditions were also reported (63). Therefore, appropriate bioreactors should be chosen according to their fermentation conditions. In addition, different fermentation approaches may get different 1,3-PD yield or productivity, including batch, fed-batch, continuous feed and two-step continuous feed fermentation. The most common are batch and fed-batch fermentation. Production parameters of 1,3-PD are given in Table $3(36,70,72-75)$.

\section{FUTURE PROSPECTS}

With the increasing prosperity of the global economy, the demand for energy sources is also increasing. In order to release the stress of the depletion of non-renewable resources and an unsustainable environment, efforts are recently being made worldwide to minimize the utilization of fossil fuels and to purify the biological routes with the purpose of avoiding bulk chemicals. The biodiesel production and its conversion cater to this sustainable tendency. The boom of genetic engineering and analogous biotechnology enables to debottleneck 1,3-PD production by microorganisms. Future concerns and strategies about genetically engineered bacteria are mainly embodied in the following respects. The first is to acquire new gene resources with the metagenomics technology. For example, the genes that allow conversion of glycerol to 1,3-PD can be cloned into a bacterium producing glycerol from sugars, which may resolve the problem of substrate inhibition. The second is to improve the producers by metabolic engineering. Specific genes or metabolic pathways can be knocked in or out in order to achieve improved microbial features. These two approaches focus on the genetic engineering modification. Due to the randomness of changed genes by conventional mutagenesis methods, the isolation of producers with high titre or productivity is a time-consuming work. Therefore, the third concern is to design satisfying facilities to improve the work efficiency.

On the other hand, the downstream processing of 1,3-PD development is also an important concern. The lack of efficient purification strategy is a hindrance to the commercialization of 1,3-PD. The fermentation media contain multiple components, such as surplus glycerol, nutrient content, byproducts and salts. This challenge has to be resolved to make purified 1,3-PD economically available. The major methods for the purification and recovery that have been studied are reactive extraction, liquid-liquid extraction, evaporation, distillation, membrane filtration, pervaporation and ion exchange chromatography. After the separation, the other value-added byproducts can also be recovered, which also caters for the concept of sustainable development (76).

Table 3. Different parameters for 1,3-propanediol production by various strains

\begin{tabular}{|c|c|c|c|c|}
\hline Method & Description & Parameter value & Strain & Reference \\
\hline \multirow{3}{*}{ Batch fermentation } & \multirow{3}{*}{$\begin{array}{l}\text { Easy operation, short cycle, low } \\
\text { contamination rate, low titre or } \\
\text { yield, complicated kinetic parameter } \\
\text { measurements }\end{array}$} & $\gamma($ titre $)=78.5 \mathrm{~g} / \mathrm{L}$ & C. diolis GSHM 2 & (72) \\
\hline & & $\gamma=0.65 \mathrm{~mol} / \mathrm{mol}$ & C. butyricum YJH-09 & (73) \\
\hline & & $r=0.78 \mathrm{~g} /(\mathrm{L} \cdot \mathrm{h})$ & L. brevis N1E9.3.3 & (74) \\
\hline \multirow{3}{*}{ Fed-batch fermentation } & \multirow{3}{*}{$\begin{array}{l}\text { Constant substrate concentration or } \\
\text { feed rate, kinetic paremeter analysis, } \\
\text { high productivity, possibility of } \\
\text { contamination, species degeneration }\end{array}$} & $\gamma($ titre $)=87.5 \mathrm{~g} / \mathrm{L}$ & K. pneumoniae 2-1 & (36) \\
\hline & & $\gamma=0.67 \mathrm{~mol} / \mathrm{mol}$ & K. pneumoniae DSM 4799 & $(75)$ \\
\hline & & $r=3.29 \mathrm{~g} /(\mathrm{L} \cdot \mathrm{h})$ & K. pneumoniae KG1 & $(70)$ \\
\hline
\end{tabular}

$\gamma=$ yield, $r=$ productivity 
Some researchers estimated the producing costs of 1,3-PD fermentation and purification. In fermentation, one of the key factors influencing the unit price of 1,3-PD was the price of crude glycerol, whose market price in 2017 was about 300400 USD/t (77). Apart from that, in the purification process, the main expense focuses on the separation processes. Jiyan et al. (78) analyzed the cost of three consecutive separation processes after biological fermentation. The cost of each separate step is about 2200 USD/t. In addition, the labour cost or other extra costs also increase the price. Since the improvement of final concentration and conversion rate can reduce the cost of production, the optimization and improvement of 1,3-PD separation should still be strengthened so as to realize its further industrialization application in terms of the market price of 1,3-PD (4000 USD/t).

\section{CONCLUSIONS}

Sustainable development and resource recycling including bioconversion of 1,3-propanediol (1,3-PD) from glycerol is a perpetual theme. The biological methods for 1,3-PD production using engineered strains is just a starting point. Various strategies have been dedicated to maximizing the production potential. Genetic engineering provides accurate and directional ways to alter the producers and improve the yield, enabling the customization of metabolic pathway. Conventional mutagenesis enlarges the possibility of obtaining desired performances which can be screened. Advantages and disadvantages coexist in both genetic and conventional methods and a lot more work needs to be done to overcome the obstacles in industrial biosynthesis of 1,3-PD. The joint implementation of the existing methods or the exploration of new biotechnologies is the only way forward to find genetically engineered strains that produce 1,3-PD.

\section{ACKNOWLEDGEMENTS}

This work was supported by the National Natural Science Foundation of China (grant no. 31571806), High-level talents project of Six Talent Peaks in Jiangsu Province (grant no. SWYY-018) and China Postdoctoral Science Foundation (grant no. 2017M621657).

\section{REFERENCES}

1. Kaur G, Srivastava AK, Chand S. Advances in biotechnological production of 1,3-propanediol. Biochem Eng J. 2012;64:106-18. https://doi.org/10.1016/j.bej.2012.03.002

2. Clomburg JM, Gonzalez R. Anaerobic fermentation of glycerol: A platform for renewable fuels and chemicals. Trends Biotechnol. 2013;31(1):20-8. https://doi.org/10.1016/j.tibtech.2012.10.006

3. Qi X, Yun J, Qi Y, Zhang H, Wang F, Guo Q, Cao Z. Expression and characterization of a novel 1,3-propanediol dehydrogenase from Lactobacillus brevis. Appl Biochem Biotech.
2016;179(6):959-72

https://doi.org/10.1007/s12010-016-2043-6

4. Qi X, Deng W, Wang F, Guo Q, Chen H, Wang L, et al. Molecular cloning, co-expression, and characterization of glycerol dehydratase and 1,3-propanediol dehydrogenase from Citrobacter freundii. Mol Biotechnol. 2013;54(2):469-74. https://doi.org/10.1007/s12033-012-9585-9

5. Chatzifragkou A, Dietz D, Komaitis M, Zeng AP, Papanikolaou S. Effect of biodiesel-derived waste glycerol impurities on biomass and 1,3-propanediol production of Clostridium butyricum VPI 1718. Biotechnol Bioeng. 2010;107(1):76-84. https://doi.org/10.1002/bit.22767

6. Maervoet VET, De Mey M, Beauprez J, De Maeseneire S, Soetaert WK. Enhancing the microbial conversion of glycerol to 1,3-propanediol using metabolic engineering. Org Process Res Dev. 2011;15(1):189-202. https://doi.org/10.1021/op1001929

7. González-Pajuelo M, Meynial-Salles I, Mendes F, Andrade JC, Vasconcelos I, Soucaille P. Metabolic engineering of Clostridium acetobutylicum for the industrial production of 1,3-propanediol from glycerol. Metab Eng. 2005;7:329-36. https://doi.org/10.1016/j.ymben.2005.06.001

8. Metsoviti M, Zeng AP, Koutinas AA, Papanikolaou S. Enhanced 1,3-propanediol production by a newly isolated Citrobacter freundii strain cultivated on biodiesel-derived waste glycerol through sterile and non-sterile bioprocesses. J Biotechnol. 2013;163(4):408-18. https://doi.org/10.1016/j.jbiotec.2012.11.018

9. Zhang G, Yang G, Wang X, Guo Q, Li Y, Li J. Influence of blocking of 2,3-butanediol pathway on glycerol metabolism for 1,3-propanediol production by Klebsiella oxytoca. Appl Biochem Biotechnol. 2012;168(1):116-28. https://doi.org/10.1007/s12010-011-9363-3

10. Zhu C, Fang B, Wang S. Effects of culture conditions on the kinetic behavior of 1,3-propanediol fermentation by Clostridium butyricum with a kinetic model. Bioresour Technol. 2016;212:130-7. https://doi.org/10.1016/j.biortech.2016.04.028

11. Chatzifragkou A, Papanikolaou S, Dietz D, Doulgeraki Al, Nychas GJE, Zeng AP. Production of 1,3-propanediol by Clostridium butyricum growing on biodiesel-derived crude glycerol through a non-sterilized fermentation process. Appl Microbiol Biotechnol. 2011;91(1):101-12. https://doi.org/10.1007/s00253-011-3247-x

12. Celińska E, Drożdżyńska A, Jankowska M, Białas W, Czaczyk K, Grajek W. Genetic engineering to improve 1,3-propanediol production in an isolated Citrobacter freundii strain. Process Biochem. 2015;50(1):48-60. https://doi.org/10.1016/j.procbio.2014.09.001

13. Yen HW, Li FT, Chang JS. The influences of $\mathrm{pH}$ control strategies on the distribution of 1,3-propanediols and 2,3-butanediols production by an isolated indigenous Klebsiella sp. Ana-WS5. Bioresour Technol. 2014;159:292-6. https://doi.org/10.1016/j.biortech.2014.02.115 
14. Pyne ME, Sokolenko S, Liu X, Srirangan K, Bruder MR, Aucoin $M G$, et al. Disruption of the reductive 1,3-propanediol pathway triggers production of 1,2-propanediol for sustained glycerol fermentation by Clostridium pasteurianum. Appl Environ Microbiol. 2016;82(17):5375-88.

https://doi.org/10.1128/AEM.01354-16

15. Tsuruno K, Honjo H, Hanai T. Enhancement of 3-hydroxypropionic acid production from glycerol by using a metabolic toggle switch. Microb Cell Fact. 2015;14:155.

https://doi.org/10.1186/s12934-015-0342-1

16. Szymanowska-Powałowska D, Leja K. An increasing of the efficiency of microbiological synthesis of 1,3-propanediol from crude glycerol by the concentration of biomass. Electron J Biotechnol. 2014;17(2):72-8.

https://doi.org/10.1016/j.ejbt.2013.12.010

17. Dietz D, Zeng AP. Efficient production of 1,3-propanediol from fermentation of crude glycerol with mixed cultures in a simple medium. Bioprocess Biosyst Eng. 2014;37(2):225-33. https://doi.org/10.1007/s00449-013-0989-0

18. Moscoviz R, Trably E, Bernet N. Consistent 1,3-propanediol production from glycerol in mixed culture fermentation over a wide range of pH. Biotechnol Biofuels. 2016;9:32.

https://doi.org/10.1186/s13068-016-0447-8

19. Apiwatanapiwat W, Vaithanomsat P, Tachaapaikoon C, Ratanakhanokchai K, Kosugi A. Effect of cassava pulp supplement on 1,3-propanediol production by Clostridium butyricum. J Biotechnol. 2016;230:44-6.

https://doi.org/10.1016/j.jbiotec.2016.05.016

20. Maervoet VET, De Maeseneire SL, Avci FG, Beauprez J, Soetaert WK, De Mey M. High yield 1,3-propanediol production by rational engineering of the 3-hydroxypropionaldehyde bottleneck in Citrobacter werkmanii. Microb Cell Fact. 2016;15:23.

https://doi.org/10.1186/s12934-016-0421-y

21. Oh BR, Hong WK, Heo SY, Luo LH, Kondo A, Seo JW, Kim CH. The production of 1,3-propanediol from mixtures of glycerol and glucose by a Klebsiella pneumoniae mutant deficient in carbon catabolite repression. Bioresour Technol. 2013;130:719-24.

https://doi.org/10.1016/j.biortech.2012.12.076

22. Szymanowska-Powałowska D. The effect of high concentrations of glycerol on the growth, metabolism and adaptation capacity of Clostridium butyricum DSP1. Electron J Biotechnol. 2015;18:128-33.

https://doi.org/10.1016/j.ejbt.2015.01.006

23. Horng YT, Chang KC, Chou TC, Yu CJ, Chien CC, Wei YH, Soo PC. Inactivation of dhaD and dhaK abolishes by-product accumulation during 1,3-propanediol production in Klebsiella pneumoniae. J Ind Microbiol Biotechnol. 2010;37(7):707-16. https://doi.org/10.1007/s10295-010-0714-9

24. Dishisha T, Pereyra LP, Pyo SH, Britton RA, Hatti-Kaul R. Flux analysis of the lactobacillus reuteri propanediol-utilization pathway for production of 3-hydroxypropionaldehyde, 3-hydroxypropionic acid and 1,3-propanediol from glycerol. Microb Cell Fact. 2014;13:76.

https://doi.org/10.1186/1475-2859-13-76

25. Jiang W, Zhuang Y, Wang S, Fang B. Directed evolution and resolution mechanism of 1,3-propanediol oxidoreductase from Klebsiella pneumoniae toward higher activity by error-prone PCR and bioinformatics. PLoS ONE. 2015;10(11):e0141837.

https://doi.org/10.1371/journal.pone.0141837

26. Celińska E. Debottlenecking the 1,3-propanediol pathway by metabolic engineering. Biotechnol Adv. 2010;28(4):519-30. https://doi.org/10.1016/j.biotechadv.2010.03.003

27. Saier Jr MH, Yen MR, Noto K, Tamang DG, Elkan C. The transporter classification database: Recent advances. Nucleic Acids Res. 2009;37:D274-8.

https://doi.org/10.1093/nar/gkn862

28. Da Silva GP, de Lima CJB, Contiero J. Production and productivity of 1,3-propanediol from glycerol by Klebsiella pneumoniae GLC29. Catal Today. 2015;257(Part 2):259-66.

https://doi.org/10.1016/j.cattod.2014.05.016

29. Sardari RRR, Dishisha T, Pyo SH, Hatti-Kaul R. Biotransformation of glycerol to 3-hydroxypropionaldehyde: Improved production by in situ complexation with bisulfite in a fed-batch mode and separation on anion exchanger. J Biotechnol. 2013;168(4):534-42.

https://doi.org/10.1016/j.jbiotec.2013.09.009

30. Kumar V, Ashok S, Park S. Recent advances in biological production of 3-hydroxypropionic acid. Biotechnol Adv. 2013;31(6):945-61.

https://doi.org/10.1016/j.biotechadv.2013.02.008

31. Gungormusler-Yilmaz M, Cicek N, Levin DB, Azbar N. Cell immobilization for microbial production of 1,3-propanediol. Crit Rev Biotechnol. 2016;36(3):482-94. https://doi.org/10.3109/07388551.2014.992386

32. Szymanowska-Powałowska D, Kubiak P. Effect of 1,3-propanediol, organic acids, and ethanol on growth and metabolism of Clostridium butyricum DSP1. Appl Microbiol Biotechnol. 2015;99(7):3179-89.

https://doi.org/10.1007/s00253-014-6292-4

33. Colin T, Bories A, Moulin G. Inhibition of Clostridium butyricum by 1,3-propanediol and diols during glycerol fermentation. Appl Microbiol Biotechnol. 2000;54(2):201-5. https://doi.org/10.1007/s002530000365

34. Kaur G, Srivastava AK, Chand S. Debottlenecking product inhibition in 1,3-propanediol fermentation by in-situ product recovery. Bioresour Technol. 2015;197:451-7.

https://doi.org/10.1016/j.biortech.2015.08.101

35. Maervoet VE, De Maeseneire SL, Avci FG, Beauprez J, Soetaert WK, De Mey M. 1,3-Propanediol production with Citrobacter werkmanii DSM17579: Effect of a dhaD knock-out. Microb Cell Fact. 2014;13:70.

https://doi.org/10.1186/1475-2859-13-70 
36. Chen L, Ma C, Wang R, Yang J, Zheng H. Deletion of IdhA and aldH genes in Klebsiella pneumoniae to enhance 1,3-propanediol production. Biotechnol Lett. 2016;38(10):1769-74. https://doi.org/10.1007/s10529-016-2155-7

37. Lin J, Zhang Y, Xu D, Xiang G, Jia Z, Fu S, Gong H. Deletion of poxB, pta, and ackA improves 1,3-propanediol production by Klebsiella pneumoniae. Appl Microbiol Biotechnol. 2016;100(6):2775-84.

https://doi.org/10.1007/s00253-015-7237-2

38. Durgapal M, Kumar V, Yang TH, Lee HJ, Seung D, Park S. Production of 1,3-propanediol from glycerol using the newly isolated Klebsiella pneumoniae J2B. Bioresour Technol. 2014;159:223-31. https://doi.org/10.1016/j.biortech.2014.01.126

39. Zhu JG, Li S, Ji XJ, Huang H, Hu N. Enhanced 1,3-propanediol production in recombinant Klebsiella pneumoniae carrying the gene yqhD encoding 1,3-propanediol oxidoreductase isoenzyme. World J Microbiol Biotechnol. 2009;25(7):1217-23.

https://doi.org/10.1007/s11274-009-0005-7

40. Cui YL, Zhou JJ, Gao LR, Zhu CQ, Jiang X, Fu SL, Gong H. Utilization of excess NADH in 2,3-butanediol-deficient Klebsiella pneumoniae for 1,3-propanediol production. J Appl Microbiol. 2014;117:690-8.

https://doi.org/10.1111/jam.12588

41. Ashok S, Raj SM, Rathnasingh C, Park S. Development of recombinant Klebsiella pneumoniae $\Delta$ dhaT strain for the co-production of 3-hydroxypropionic acid and 1,3-propanediol from glycerol. Appl Microbiol Biotechnol. 2011;90:1253-65.

https://doi.org/10.1007/s00253-011-3148-z

42. Oh BR, Seo JW, Heo SY, Luo LH, Hong WK, Park DH, Kim CH. Efficient production of 1,3-propanediol from glycerol upon constitutive expression of the 1,3-propanediol oxidoreductase gene in engineered Klebsiella pneumoniae with elimination of by-product formation. Bioprocess Biosyst Eng. 2013;36(6):757-63.

https://doi.org/10.1007/s00449-013-0901-y

43. Kumar V, Durgapal M, Sankaranarayanan M, Somasundar A, Rathnasingh C, Song HH, et al. Effects of mutation of 2,3-butanediol formation pathway on glycerol metabolism and 1,3-propanediol production by Klebsiella pneumoniae J2B. Bioresour Technol. 2016;214:432-40.

https://doi.org/10.1016/j.biortech.2016.04.032

44. Oh BR, Seo JW, Heo SY, Hong WK, Luo LH, Kim S, et al. Optimization of culture conditions for 1,3-propanediol production from glycerol using a mutant strain of Klebsiella pneumoniae. Appl Biochem Biotechnol. 2012;166(1):127-37.

https://doi.org/10.1007/s12010-011-9409-6

45. Li X, Zhang L, Gao D, Shi W, Fan Y. Progress on the production of 1,3-propanediol by fermentation. Chem Ind Eng Progress. 2014;36(4):1395-403 (in Chinese).
46. Jiang W, Wang S, Wang Y, Fang B. Key enzymes catalyzing glycerol to 1,3-propanediol. Biotechnol Biofuels. 2016;9:57. https://doi.org/10.1186/s13068-016-0473-6

47. Biebl H, Menzel K, Zeng AP, Deckwer WD. Microbial production of 1,3-propanediol. Appl Microbiol Biotechnol. 1999;52(3):289-97. https://doi.org/10.1007/s002530051523

48. Przystałowska H, Zeyland J, Szymanowska-Powałowska D, Szalata M, Słomski R, Lipiński D. 1,3-Propanediol production by new recombinant Escherichia coli containing genes from pathogenic bacteria. Microbiol Res. 2015;171:1-7. https://doi.org/10.1016/j.micres.2014.12.007

49. Tang X, Tan Y, Zhu H, Zhao K, Shen W. Microbial conversion of glycerol to 1,3-propanediol by an engineered strain of Escherichia coli. Appl Environ Microbiol. 2009;75(6):1628-34. https://doi.org/10.1128/AEM.02376-08

50. Lu S, Xiong J, Zhu Y, Guo F, Meng Q. Screening of 1,3-propanediol high yield strain by UV mutagenesis of protoplast. Chinese J Bioprocess Eng. 2011;19(3):11-6 (in Chinese).

51. Zhu XL, Nan N, Xiu ZL. Complex mutation of Klebsiella pneumoniae producing 1,3-propanediol from biodiesel-derived glycerol. Chinese J Process Eng. 2011;11(6):10307 (in Chinese).

52. Du C, Zhang Y, Li Y, Cao Z. Novel redox potential-based screening strategy for rapid isolation of Klebsiella pneumoniae mutants with enhanced 1,3-propanediol-producing capability. Appl Environ Microbiol. 2007;73(14):4515-21. https://doi.org/10.1128/AEM.02857-06

53. Otte B, Grunwaldt E, Mahmoud O, Jennewein S. Genome shuffling in Clostridium diolis DSM 15410 for improved 1,3-propanediol production. Appl Environ Microbiol. 2009;75(24):7610-6.

https://doi.org/10.1128/AEM.01774-09

54. Wang B, Liu M, Du C, Huang Z, Shen J, Cao Z. Screening of Klebsiella pneumoniae mutation for the production of 1,3-propanediol. China Biotechnol. 2006;26(6):59-65 (in Chinese).

55. Li F, Liu C, Zheng Y, Wang Z. Breeding of strain Clostridium butyricum producing 1,3-propanediol. Biotechnology. 2005;1(1):34-5 (in Chinese).

56. Pitsikas P, Patapas JM, Cupples CG. Mechanism of 2-aminopurine-stimulated mutagenesis in Escherichia coli. Mutat Res. 2004;550(1-2):25-32. https://doi.org/10.1016/j.mrfmmm.2004.01.008

57. Ferguson LR, Denny WA. Genotoxicity of non-covalent interactions: DNA intercalators. Mutat Res. 2007;623(1-2):1423.

https://doi.org/10.1016/j.mrfmmm.2007.03.014

58. Sivaramakrishnan R, Incharoensakdi A. Enhancement of lipid production in Scenedesmus sp. by UV mutagenesis and hydrogen peroxide treatment. Bioresour Technol. 2017;235:366-70.

https://doi.org/10.1016/j.biortech.2017.03.102 
59. Albertos I, Martín-Diana AB, Cullen PJ, Tiwari BK, Ojha SK, Bourke $\mathrm{P}$, et al. Effects of dielectric barrier discharge (DBD) generated plasma on microbial reduction and quality parameters of fresh mackerel (Scomber scombrus) fillets. Innov Food Sci Emerg Technol. 2017;44:117-22. https://doi.org/10.1016/j.ifset.2017.07.006

60. Dong XY, Li S, Hou YM, Xiu ZL. Mutagensis of strain Klebsiella pneumoniae producing 1,3-propanediol by cold plasma at atmospheric pressure. Chinese J Process Eng. 2008;8(3):555-60 (in Chinese).

61. Dong XY, Xiu Z, Li S, Hou Y, Zhang D, Ren C. Dielectric barrier discharge plasma as a novel approach for improving 1,3-propanediol production in Klebsiella pneumoniae. Biotechnol Lett. 2010;32(9):1245-50. https://doi.org/10.1007/s10529-010-0284-y

62. Dong XY, Xiu ZL, Hou YM, Li S, Zhang DJ, Ren CS. Enhanced production of 1,3-propanediol in Klebsiella pneumoniae induced by dielectric barrier discharge plasma in atmospheric air. IEEE Trans Plasma Sci. 2009;37(6):920-6. https://doi.org/10.1109/TPS.2009.2017749

63. Gordon AJ, Burns PA, Glickman BW. N-Methyl-N'-nitro-N-nitrosoguanidine-induced mutation in a RecA strain of Escherichia coli. Mutat Res. 1988;201(1):219-28. https://doi.org/10.1016/0027-5107(88)90129-7

64. Guo T, Tang Y, Zhang QY, Du TF, Liang DF, Jiang M, Ouyang JP. Clostridium beijerinckii mutant with high inhibitor tolerance obtained by low-energy ion implantation. J Ind Microbiol Biotechnol. 2012;39(3):401-7.

https://doi.org/10.1007/s10295-011-1017-5

65. Cheng M, Cui CB, Li CW, Tian CK. Chemical mutation technique applied in microorganism breeding. J Int Pharm Res. 2009;36(6):412-7 (in Chinese). https://doi.org/10.13220/j.cnki.jipr.2009.06.001

66. Yu YJ, Li ZK, Liu Y, Xu DD, Wang FH. New combined mutagenesis for screening of high-yielding 1,3-propanediol strains. Ind Microbiol. 2016;46(1):47-52 (in Chinese).

67. Abbad-Andaloussi S, Manginot-Dürr C, Amine J, Petitdemange $\mathrm{E}$, Petitdemange $\mathrm{H}$. Isolation and characterization of Clostridium butyricum DSM 5431 mutants with increased resistance to 1,3-propanediol and altered production of acids. Appl Environ Microbiol. 1995;61(12):4413-7.

68. Gallardo R, Alves M, Rodrigues LR. Influence of nutritional and operational parameters on the production of butanol or 1,3-propanediol from glycerol by a mutant Clostridium pasteurianum. N Biotechnol. 2017;34:59-67. https://doi.org/10.1016/j.nbt.2016.03.002
69. Dong XY, Teng H, Xiu ZL. Selection of strain exposed under plasma discharge with enhanced 1,3-propanediol production and kinetic analysis of batch fermentation. Chin J Process Eng. 2011;11(2):304-11 (in Chinese).

70. Zhao L, Zheng Y, Ma X, Wei D. Effects of over-expression of glycerol dehydrogenase and 1,3-propanediol oxidoreductase on bioconversion of glycerol into 1,3-propanediol by Klebsiella pneumoniae under micro-aerobic conditions. Bioproc Biosyst Eng. 2009;32(3):313-20. https://doi.org/10.1007/s00449-008-0250-4

71. Kalinowski DP, Larimer FW, Plewa MJ. Analysis of spontaneous frameshift mutations in REV1 and rev1-1 strains of Saccharomyces cerevisiae. Mutat Res. 1995;331(1):149-59. https://doi.org/10.1016/0027-5107(95)00064-P

72. Wischral D, Zhang J, Cheng C, Lin M, De Souza LMG, Pessoa FLP, et al. Production of 1,3-propanediol by Clostridium beijerinckii DSM 791 from crude glycerol and corn steep liquor: Process optimization and metabolic engineering. Bioresour Technol. 2016;212:100-10. http://doi.org/10.1016/j.biortech.2016.04.020

73. Yun J, Yang M, Magocha TA, Zhang H, Xue Y, Zhang G, et al. Production of 1,3-propanediol using a novel 1,3-propanediol dehydrogenase from isolated Clostridium butyricum and co-biotransformation of whole cells. Bioresour Technol. 2018;247:838-43.

https://doi.org/10.1016/j.biortech.2017.09.180

74. Vivek N, Pandey A, Binod P. Biological valorization of pure and crude glycerol into 1,3-propanediol using a novel isolate Lactobacillus brevis N1E9.3.3. Bioresour Technol. 2016;213:222-30.

https://doi.org/10.1016/j.biortech.2016.02.020

75. Jun SA, Moon C, Kang CH, Kong SW, Sang BI, Um Y. Microbial fed-batch production of 1,3-propanediol using raw glycerol with suspended and immobilized Klebsiella pneumoniae. Appl Biochem Biotechnol. 2010;161(1-8):491-501. https://doi.org/10.1007/s12010-009-8839-x

76. Saxena RK, Anand P, Saran S, Isar J. Microbial production of 1,3-propanediol: Recent developments and emerging opportunities. Biotechnol Adv. 2009;27(6):895-913. https://doi.org/10.1016/j.biotechadv.2009.07.003

77. Chen XB, Su DG. PDO industry status and development suggestions. Techno-Economics in Petrochemicals. 2017;33(6):1-4 (in Chinese).

78. Wang JY, Teng H, Xiu ZL. Cost analysis on three separation processes in microbial production of 1,3-propanediol. Chem Ind Eng Prog. 2012;31(1) (in Chinese). 